\title{
Isolation of a Bacillus safensis from mine tailings in Peru, genomic characterization and characterization of its cyanide- degrading enzyme CynD
}

Santiago Justo Arevalo*1,2, Daniela Zapata Sifuentes ${ }^{1,2}$, Andrea Cuba Portocarrero ${ }^{1}$, Michella Brescia Reategui ${ }^{1}$, Claudia Monge Pimentel ${ }^{1}$, Layla Farage Martins ${ }^{2}$, Paulo Marques Pierry ${ }^{2}$, Carlos Morais Piroupo ${ }^{2}$, Alcides Guerra Santa Cruz ${ }^{1}$, Mauro Quiñones Aguilar $^{1}$, Chuck Shaker Farah², João Carlos Setubal' ${ }^{2}$, Aline Maria da Silva ${ }^{2}$

1.- Facultad de Ciencias Biológicas, Universidad Ricardo Palma, Lima, Peru.

2.- Departamento de Bioquímica, Instituto de Química, Universidade de São Paulo, São Paulo, Brazil.

*Correspondence: santiago.jus.are@usp.br

\section{ABSTRACT}

Cyanide is widely used in industry as a potent lixiviant due to its capacity to tightly bind metals. This property imparts cyanide enormous toxicity to all known organisms. Thus, industries that utilize this compound must reduce its concentration in recycled or waste waters. Physical, chemical, and biological treatments have been used for cyanide remediation; however, none of them meet all the desired characteristics: efficiency, low cost and low environmental impact. A better understanding of metabolic pathways and biochemistry of enzymes involved in cyanide degradation is a necessary step to improve cyanide bioremediation efficacy to satisfy the industry requirements. Here, we used several approaches to explore this topic. We have isolated three cyanide-degrading Bacillus strains from water in contact with mine tailings from Lima, Peru, and classified them as Bacillus safensis PER-URP-08, Bacillus licheniformis PER-URP-12, and Bacillus subtilis PER-URP-17 based on 16S rRNA gene sequencing and core genome analyses. Additionally, core genome analyses of 132 publicly available genomes of Bacillus pumilus group including $B$. safensis and $B$. altitudinis allowed us to reclassify some strains and identify two strains that did not match with any known species of the Bacillus pumilus group. We searched for possible routes of cyanide-degradation in the genomes of these three strains and identified putative B. licheniformis PER-URP-12 and B. subtilis PERURP-17 rhodaneses and $B$. safensis PER-URP-08 cyanide dihydratase (CynD) sequences possibly involved cyanide degradation. We identified characteristic $\mathrm{C}$-terminal residues that differentiate CynD from B. pumilus and B. safensis, and showed that, differently from CynD from B. pumilus $\mathrm{C} 1$, recombinant CynD from the Bacillus safensis PER-URP-08 strain remains active up to $\mathrm{pH} 9$ and presents a distinct oligomerization pattern at $\mathrm{pH} 8$ and 9. Moreover, transcripts of $B$. safensis PER-URP-08 CynD (CynD PER-URP-08) are strongly induced in the presence of cyanide. Our results warrant further investigation of $B$. safensis PER-URP-08 and CynD PER-URP-08 as potential tools for cyanide-bioremediation.

\section{INTRODUCTION}

Cyanide is a highly toxic compound used in several industrial processes (Mudder et al., 2004) given its capacity to form tight complexes with different metals (Dash et al., 2009) (Hendry-Hofer et al., 2019; Leavesley et al., 2008). Industries that generate cyanidecontaining wastes must reduce its concentration before discarding them to the environment, and as such proper strategies have to be implemented for cyanide 
remediation (Kuyucak \& Akcil, 2013). Cyanide bioremediation by bacteria that express nitrilases is one possible low-cost and environmental-friendly approach (Dash et al., 2009).

Nitrilases are a superfamily of proteins characterized by a tertiary structure consisting of an alpha-beta-beta-alpha fold and a dimer as a basic unit. This superfamily has been divided into thirteen branches with branch one corresponding to enzymes that cleave the nitrile group into ammonia and its respective carboxylic acid. The other twelve branches are structurally similar but their catalytic activity does not involve cleavage of nitriles (Pace \& Brenner, 2001).

Two types of nitrilases can degrade cyanide through a hydrolytic pathway: cyanide hydratases (CHTs) and cyanide dihydratases (CynDs). CHTs convert cyanide into formamide using one water molecule in the reaction and are present in fungal genomes. The first enzyme described with this activity was from Stemphylium loti (Fry \& Millar, 1972). Subsequently, CHTs from other fungal species have been studied such as: Fusarium solani, Fusarium oxysporum, Gloeocercospora sorghi, Leptosphaeria maculans, and Aspergillus niger (Akinpelu et al., 2018; Dumestre et al., 1997; Ping Wang; Hans D. VanEtten, 1992; Rinágelová et al., 2014; Sexton \& Howlett, 2000). On the other hand, only the CynDs from B. pumilus, P. stutzeri and Alcaligenes xylosoxidans (Ingvorsen et al., 1991; Meyers et al., 1993; Watanabe et al., 1998) have been experimentally tested. The reaction catalyzed by CynDs generates formic acid and ammonia using two molecules of water. Both, CynDs and CHTs, typically form large helical aggregates of several subunits (Thuku et al., 2009). For example, the CynD of Bacillus pumilus is reported to form an 18subunit oligomer (Jandhyala et al., 2003) whereas the homolog in Pseudomonas stutzeri forms a 14-subunit oligomer (Sewell et al., 2003)

Several Bacillus species have been shown to be capable of metabolizing cyanide using different routes, for instance: B-cyanoalanine synthase in Bacillus megaterium (Castric \& Strobel, 1969), gamma-cyano-alpha-aminobutyric acid synthase in B. stearothermophilus (Omura et al., 2003), rhodanase in Bacillus cereus (Itakorode et al., 2019), and CynD in Bacillus pumilus (Meyers et al., 1993). On the other hand, some other cyanide-degrading Bacillus have still unknown metabolic routes (Al-Badri et al., 2020; Javaheri Safa et al., 2017; Mekuto et al., 2014).

The Bacillus pumilus group consists mainly of three species: Bacillus altitudinis, Bacillus safensis and Bacillus pumilus. These three species share more than $99 \%$ sequence identity in their 16S rRNA gene (Liu et al., 2013), hampering taxonomical classification based solely on this locus. Studies using multiple phylogenetic markers have demonstrated that $\sim 50 \%$ of the Bacillus pumilus group genomes deposited in NCBI database could be misclassified (Espariz et al., 2016).

81 It is plausible to speculate that CynDs isolated from Bacillus strains from diverse 82 environments could present different properties that could be better for industrial 83 applications. Therefore, the characterization of CynD from other species can expand our understanding on the functioning and plasticity of this enzyme. Furthermore, some aspects of the biology of this enzyme have not been thoroughly studied. For instance, it is known that the oligomeric state of CynD is strongly pH-dependent (Jandhyala et al., 2003); however, the effect on oligomerization at pHs greater than 9 has not been reported. Also, it 88 is unknown whether CynD is constitutively expressed in basal metabolism or is part of a 89 specific physiological response, for instance, induced by the presence of cyanide.

90 Here, we describe the isolation of three indigenous Bacillus strains from mine tailing in 91 Peru and their respective genome sequences. We selected a strain that was most efficient 
in cyanide degradation and investigated its phylogenetic relationship with other species of the Bacillus pumilus group. We identified a gene coding for a cyanide dihydratase (CynD) that is most likely the enzyme responsible for cyanide degradation in this selected strain. A recombinant CynD was expressed and purified, its catalytic parameters were determined, and the quaternary structure was studied at different pHs. We also demonstrated that CynD transcripts are strongly induced in the presence of cyanide.

\section{MATERIAL AND METHODS}

\section{Isolation of cyanide-degrading strains}

Water in contact with mine tailing was collected from a river near Casapalca and La Oroya mines located in San Mateo de Huanchor (Latitude -11.4067 Longitude -76.3361 at 4221 MASL). The sample was collected in $2 \mathrm{~L}$ sterile bottles and transported at $4{ }^{\circ} \mathrm{C}$.

One hundred $\mathrm{mL}$ of the sample was added to an Erlenmeyer flask containing $20 \mathrm{ml}$ of 21 $\mathrm{g} / \mathrm{L}$ sodium carbonate, $9 \mathrm{~g} / \mathrm{L}$ sodium bicarbonate, $5 \mathrm{~g} / \mathrm{L}$ sodium chloride and $0.5 \mathrm{~g} / \mathrm{L}$ potassium nitrate. Cultures were incubated for $12 \mathrm{~h}$ at $37{ }^{\circ} \mathrm{C}$ and after this time $1 \mathrm{mg} / \mathrm{L}$ final concentration of cyanide in the form of sodium cyanide was added. The cultures were incubated for another $24 \mathrm{~h}$ at $37^{\circ} \mathrm{C}$. Samples of the medium were streaked in petri dishes with nutrient agar ( $5 \mathrm{~g} / \mathrm{L}$ peptone, $5 \mathrm{~g} / \mathrm{L}$ yeast extract, $5 \mathrm{~g} / \mathrm{L}$ sodium chloride and $1 \%$ agar) and incubated at $37{ }^{\circ} \mathrm{C}$ for $24 \mathrm{~h}$. Single colonies were isolated in nutrient broth $(5 \mathrm{~g} / \mathrm{L}$ peptone, $5 \mathrm{~g} / \mathrm{L}$ yeast extract, $5 \mathrm{~g} / \mathrm{L}$ sodium chloride) supplemented with $20 \%$ glycerol and stored at $-80^{\circ} \mathrm{C}$.

Strains stored at $-80^{\circ} \mathrm{C}$ were reactivated at $37^{\circ} \mathrm{C}$ in nutrient agar by streaking a sample. One colony was inoculated in fresh nutrient broth and incubated at $37^{\circ} \mathrm{C}$ overnight at 100 g. Next, the optical density at $600 \mathrm{~nm}\left(\mathrm{OD}_{600 \mathrm{~nm}}\right)$ of the culture was adjusted to 0.8 and 1 $\mathrm{mL}$ was centrifuged at $6000 \mathrm{~g}$ for $3 \mathrm{~min}$. The pellet was washed twice with $0.2 \mathrm{M} \mathrm{Tris}-\mathrm{HCl}$ $\mathrm{pH} 8$ and resuspended in $1 \mathrm{~mL}$ of $0.2 \mathrm{M}$ Tris- $\mathrm{HCl} \mathrm{pH} 8$ supplemented with $0.2 \mathrm{M} \mathrm{NaCN}$. After $2 \mathrm{~h}$ of incubation at $30{ }^{\circ} \mathrm{C}$, the culture was centrifuged at $6000 \mathrm{~g}$ and $10 \mu \mathrm{L}$ of the supernatant was taken and diluted in $90 \mu \mathrm{L}$ of milliQ water. Then, $200 \mathrm{uL}$ of $0.5 \%$ picric acid in $0.25 \mathrm{M}$ sodium carbonate was added and heated for $6 \mathrm{~min}$ at $100{ }^{\circ} \mathrm{C}$ (Williams \& Edwards, 1980). Finally, absorbance at $520 \mathrm{~nm}$ was measured and compared to a standard curve of $\mathrm{NaCN}$.

\section{Strain identification by $16 \mathrm{~S}$ rRNA gene sequencing}

To determine the bacterial genera and/or species of the isolated strains, we used a fresh culture in nutrient agar. Five colonies from these cultures were transferred to $50 \mu \mathrm{L}$ of milliQ water and then heated to $100{ }^{\circ} \mathrm{C}$ for $3 \mathrm{~min}$ in a dry bath. The samples were centrifuged at $10000 \mathrm{~g}$ for $5 \mathrm{~min}$ and the supernatant was used as a template to amplify a fragment that includes the V6, V7 and V8 variable regions of 16S rRNA gene. One $\mu \mathrm{L}$ of the template, 25 pmol of F_primer, 5' GCACAAGCGGTGGAGCATGTGG 3', and of the R_primer, 5' GCCCGGGAACGTATTCACCG 3', were mixed with 1x Taq buffer, 1.5 mmol of $\mathrm{MgCl}_{2}, 0.2 \mathrm{mmol}$ of each dNTP, and $1 \mathrm{U}$ Taq DNA polymerase (ThermoFisher Scientific) in a final reaction of $25 \mu \mathrm{L}$. The amplification program was an initial denaturation at $94{ }^{\circ} \mathrm{C}$ for $5 \mathrm{~min}$ followed by 30 cycles at $94{ }^{\circ} \mathrm{C}$ for $45 \mathrm{sec}, 50{ }^{\circ} \mathrm{C}$ for $45 \mathrm{sec}$, and $72{ }^{\circ} \mathrm{C}$ for $1 \mathrm{~min}$, with a final extension of $10 \mathrm{~min}$ at $72{ }^{\circ} \mathrm{C}$. Five $\mu \mathrm{L}$ of the final reaction was used as a template for the sequencing reaction. Sequencing reaction was done using Big Dye terminator v3.1 cycle sequencing kit (ThermoFisher Scientific) consisting of a $1 \mathrm{x}$ sequencing buffer, 25 pmol F_primer or R_primer and $2 \mu \mathrm{L}$ of Big Dye in a final volume of $20 \mu \mathrm{L}$. The program used was an initial denaturation at $94{ }^{\circ} \mathrm{C}$ for $5 \mathrm{~min}$, followed by 40 
cycles at $94^{\circ} \mathrm{C}$ for $30 \mathrm{sec}, 50{ }^{\circ} \mathrm{C}$ for $30 \mathrm{sec}$, and $60{ }^{\circ} \mathrm{C}$ for $4 \mathrm{~min}$. After the sequencing reaction, $80 \mu \mathrm{L}$ of $70 \%$ isopropanol was added and the reaction tube was centrifuged at $4000 \mathrm{~g}$ at $4{ }^{\circ} \mathrm{C}$ for $40 \mathrm{~min}$. Then the supernatant was discarded, and the sample was resuspended in $20 \mu \mathrm{L}$ of milliQ water and injected in an ABI PRISM 3130XL genetic analyzer (ThermoFisher Scientific). The obtained sequences were used to perform BLASTn (Altschul et al., 1990) searches against the Genbank/NCBI database (Benson et al., 2013) to identify most similar sequences.

\section{Genome sequencing, assembling and annotation}

Bacterial cultures were grown in 2xTY broth (tryptone $16 \mathrm{~g} / \mathrm{L}$, yeast extract $10 \mathrm{~g} / \mathrm{L}$, and $\mathrm{NaCl} 5 \mathrm{~g} / \mathrm{L}$ ) at $37^{\circ} \mathrm{C}$ for $18 \mathrm{~h}$ at $200 \mathrm{rpm}$. Genomic DNA purification was done using the Wizard Genomic DNA Purification Kit (Promega). DNA integrity was evaluated by $1 \%$ agarose gel electrophoresis stained with SYBRSafe (Invitrogen) and by Bioanalyzer 2100 using Chips Agilent DNA 12000. DNA concentration and purity were estimated using a NanoDrop One/OneC Microvolume UV-Vis Spectrophotometer (ThermoFisher Scientific). Shotgun genomic library was prepared using the Nextera DNA Library Prep (llumina) with total DNA input of 20-35 ng. The resulting indexed DNA library was cleaned up with Agencourt AMPure XP beads (Beckman Coulter) and fragment size within the range of 200-700 bp were verified by running in the 2100 Bioanalyzer using Agilent High Sensitivity DNA chip. Fragment library quantification was performed with KAPA Library Quantification Kit. Genomic libraries prepared for each strain were pooled and subjected to a run using a an Ilumina MiSeq Reagent Kit v2 ( 2 x 250 cycles) which generated $~ 38$ million raw pairedend reads with $>75 \%$ of bases with quality score $>30$.

The genome of strain PER-URP-08 was assembled with Discovar (v. 52488) (Weisenfeld et al., 2014). The genomes of strains PER-URP-12 and PER-URP-17 were assembled with A5 (v. 20160825) (Coil et al., 2015). Both software have adapters trimming and read quality checking as part of their respective assembly processes. The tool Medusa (Bosi et al., 2015) was used to generate final genome scaffolds using three sets of five reference genomes, one for each of the genome assemblies (Table S1). The final genome assemblies were submitted to the IMG/M (Chen et al., 2021) and to the $\mathrm{NCBI}$ (Benson et al., 2013; Tatusova et al., 2016) for automatic annotation.

\section{Phylogenetic analyses and identification of nitrilases}

Annotated genomes belonging to Bacillus pumilus, Bacillus safensis or Bacillus altitudinis species in the category of "Chromosome", "Scaffold" or "Complete" were downloaded from the Genbank/NCBI (Benson et al., 2013). Using the software cd-hit (Fu et al., 2012; Li \& Godzik, 2006) we identified coding sequences that are not duplicated and present in all the genomes (core genes). A total of 1766 core genes with more than $80 \%$ identity and at least $90 \%$ coverage were used in the analysis. Core genes were aligned using MAFFT with the FFT-NS-2 algorithm (Katoh \& Standley, 2013). The resulting alignments were concatenated and used to calculate a distance matrix based on identity using Biopython (Cock et al., 2009). Phylogenetic inference by maximum likelihood was done using the concatenated alignments as the input and IQ-TREE2 (Minh et al., 2020) with the evolution model GTR+F+R3, ultrafast bootstrap 1000 (Hoang et al., 2018), and 1000 initial trees.

IMG/M tools (Chen et al., 2021) were used to identify nitrilases genes in the annotated genomes. Genes encoding the CN_hydrolase domain (PFAM code PF00795) were selected and checked regarding the genomic context and the related literature.

\section{Analysis of CynD sequences from Bacillus pumilus group genomes}


184

185

186

187

188

189

190

191

192

193

194

195

196

197

198

199

200

201

202

203

204

205

206

207

208

209

210

211

212

213

214

215

216

217

218

219

220

221

222

223

224

225

226

227

228

229

Protein sequence annotations from genomes belonging to Bacillus pumilus, Bacillus safensis or Bacillus altitudinis in the category of "Chromosome", "Scaffold" or "Complete" were downloaded from GenBank/NCBI (Benson et al., 2013) and used to construct a local database. We ran a BLASTp search (Altschul et al., 1990) using the query sequence AAN77004.1 against the constructed local database, and sequences with more than $90 \%$ identity and $100 \%$ coverage were identified as CynD orthologs. These sequences were aligned using MAFFT with the L-INS-I algorithm (Katoh \& Standley, 2013). The resulting alignment was used as an input for the phylogenetic inference by maximum likelihood using IQ-TREE2 (Minh et al., 2020) with the evolution model JTTDCMut+l (Kosiol \& Goldman, 2005), ultrafast bootstrap 1000 (Hoang et al., 2018), 1000 initial trees and -allnni option.

\section{Cloning, expression and purification of CynD}

The coding sequence for CynD was amplified from genomic DNA of strain PER-URP-08 using the primers (restriction sites appear in uppercase): F_CynD (5' ttCATATGatgacaagtatttacccgaagtttc 3'), and R_CynD (5' tttCTCGAGcacttttcttcaagcaaccc $\left.3^{\prime}\right)$ and cloned in the Ndel and Xhol sites of pET-28 plasmid. Then, this plasmid was used as a template to amplify the CynD coding sequence with a c-terminal $6 x-$ His tag using the primers F_CynD and R_2_CynD (5' tttGAATTCagtggtggtggtggtggtg 3') and cloned in the Ndel and $\bar{E}$ coRI sites of $\bar{p} \overline{E T}-11$ plasmid.

To express CynD protein, we used the Escherichia coli BL21(DE3) pLysS strain, induced by $0.3 \mathrm{mM}$ of Isopropyl B-D-1-thiogalactopyranoside for $23 \mathrm{~h}$ at $18^{\circ} \mathrm{C}$. The cells were lysed by sonication using a lysis buffer $(100 \mathrm{mM}$ Tris- $\mathrm{HCl} \mathrm{pH} 8.0,100 \mathrm{mM} \mathrm{NaCl}, 50 \mathrm{mM}$ Imidazole) and the suspension was clarified by centrifugation (13000 g). The supernatant was loaded onto Ni-NTA affinity resin (His-trap chelating $5 \mathrm{~mL}$ column), washed with 10 volumes of lysis buffer, and eluted with a gradient of $50-500 \mathrm{mM}$ Imidazole in $20 \mathrm{mM}$ Tris$\mathrm{HCl} \mathrm{pH} \mathrm{8.0,} 100 \mathrm{mM} \mathrm{NaCl}$. The eluted fractions were further purified by size exclusion chromatography using a Superdex pg 200 16/600 column and 20 mM Tris-HCl pH 8.0, 100 $\mathrm{mM} \mathrm{NaCl}$ as running buffer. The eluted fractions were examined for purity by SDS-PAGE and fractions containing pure protein were concentrated in Amicon Ultra-15 Centrifugal filter units.

\section{Enzymatic assays of recombinant CynD}

For the determination of $\mathrm{Km}$ and Vmax, enzymatic activity of recombinant CynD was measured at $\mathrm{pH} 8.0$ using the Ammonia Assay Kit (Sigma-Aldrich). A concentration of 500 $\mathrm{nM}$ of CynD was used in all reactions with the following cyanide concentrations: 0.39 , $0.625,0.78,1.25,1.56,2.5,3.125,5,6.25,12.5,25 \mathrm{mM}$, with a final volume of $111 \mathrm{uL}$ at $30{ }^{\circ} \mathrm{C}$. Measurements were taken on a plate reader, at $340 \mathrm{~nm}$ every $20 \mathrm{sec}$. Calculations of ammonia concentrations were carried out according to the manufacturer description.

To test in which optimal $\mathrm{pH}$ for CynD activity, reagent solutions were prepared $(40 \mathrm{mM}$ $\mathrm{NaCN}, 100 \mathrm{mM} \mathrm{NaCl}$ and $200 \mathrm{mM}$ Tris-HCl or N-cyclohexyl-3-aminopropanesulfonic acid (CAPS) at $\mathrm{pH} 8,9$ or 10,11 , respectively). Then, we added $5 \mu \mathrm{L}$ of $\mathrm{CynD}$ in $100 \mathrm{mM} \mathrm{NaCl}$, Tris- $\mathrm{HCl} \mathrm{pH} 8$ to $45 \mu \mathrm{L}$ of the reagent solutions to obtain a final concentration of CynD of 0 , $5,10,15$, or $20 \mu \mathrm{M}$. The reactions were incubated for $10 \mathrm{~min}$ at $37^{\circ} \mathrm{C}$. After that, $100 \mu \mathrm{L}$ of picric acid $5 \mathrm{mg} / \mathrm{mL}, 0.25 \mathrm{M} \mathrm{Na}_{2} \mathrm{CO}_{3}$ was added, and the reactions were incubated at 99 ${ }^{\circ} \mathrm{C}$ for $6 \mathrm{~min}$. Next, $30 \mu \mathrm{L}$ of this reaction was transferred to a 96-well plate and absorbance at $520 \mathrm{~nm}$ was recorded. Final cyanide concentration was estimated based on calibration curves with cyanide concentrations between $0-40 \mathrm{mM}$. 
230

231

232

233

234

235

236

237

238

239

240

241

242

243

244

245

246

247

\section{Size Exclusion Chromatography coupled to Multi-Angle Light Scattering (SEC- MALS)}

SEC-MALS analysis was used to determine the oligomeric state of recombinant CynD. Molar mass analysis was done in $100 \mathrm{mM} \mathrm{NaCl}$ and $20 \mathrm{mM}$ Tris-HCl or CAPS at $\mathrm{pH} 8,9$ or 10,11 , respectively. Protein samples $(100 \mu \mathrm{L}$ injection of $3.47 \mathrm{mg} / \mathrm{mL}(89.36 \mu \mathrm{M})$ CynD) were separated using a Superdex 200 increase 10/300 GL coupled to a MiniDAWN TREOS multi-angle light scattering system and an Optilab rEX refractive index detector. Data analysis was performed using the Astra Software package, version 7.1.1 (Wyatt Technology Corp.).

\section{Transmission electron microscopy (TEM)}

Ultra-thin carbon layer on lacey carbon-coated copper grids were negatively charged by a glow discharge of $25 \mathrm{sec}$ at $15 \mathrm{~mA}$. Four microliters of purified recombinant CynD in 20 $\mathrm{mM}$ Tris- $\mathrm{HCl} \mathrm{pH} 8.0$ and $100 \mathrm{mM} \mathrm{NaCl}$ in different concentrations $(3.25 \mathrm{mg} / \mathrm{mL}$ or 1.625 $\mathrm{mg} / \mathrm{mL}$ ) were placed in the negative charged carbon-coated copper grid for 1 minute. The grids were washed twice with MilliQ water and then stained with $2 \%$ uranyl acetate for 30 secs before air drying. Electron micrographs images were obtained using a JEOL JEM 2100 transmission electron microscope equipped with a Gatan ORIUS CCD detector at the Institute of Chemistry of the University of Sao Paulo.

\section{RT-qPCR to evaluate in vivo induction of $c y n D$ by cyanide}

Bacillus strains were grown in meat broth (meat extract $1 \mathrm{~g} / \mathrm{L}$, yeast extract $2 \mathrm{~g} / \mathrm{L}$, peptone $5 \mathrm{~g} / \mathrm{L}, \mathrm{NaCl} 5 \mathrm{~g} / \mathrm{L}, \mathrm{MnCl}_{2} 10 \mathrm{mg} / \mathrm{L}$ ) during $12 \mathrm{~h}$ at $30^{\circ} \mathrm{C}, 200 \mathrm{rpm}$. One $\mathrm{mL}$ of the culture was centrifuged at $500 \mathrm{xg}$ for $1 \mathrm{~min}$, the supernatant was transferred to a clean tube and this tube was centrifuged at $8000 \mathrm{xg}$ for $3 \mathrm{~min}$. The pellet was resuspended in $1 \mathrm{~mL}$ of $\mathrm{NaCN}\left(\left[\mathrm{CN}^{-}\right] 100 \mathrm{ppm}\right.$ ) in milliQ water. Controls were resuspended in $1 \mathrm{~mL}$ milliQ water without $\mathrm{NaCN}$. The tubes were incubated without agitation at $30^{\circ} \mathrm{C}$ for $4 \mathrm{~h}$ and $100 \mu \mathrm{L}$ were retrieved to measure cyanide concentration by the picric acid method (Williams \& Edwards, 1980). Nine hundred $\mu \mathrm{L}$ was centrifuged, and the bacterial pellet was used immediately for total RNA extraction.

Total RNA extraction was done using Trizol-chloroform protocol. Briefly, bacterial pellets were treated with $100 \mu \mathrm{L}$ of lysozyme $3 \mathrm{mg} / \mathrm{mL}$ at $37^{\circ} \mathrm{C}$ for $30 \mathrm{~min}$, and extraction was done using a mixture of $5: 1$ trizol:chloroform. After the extraction, the phase containing RNA was separated and the RNA was precipitated using isopropanol. RNA pellet was washed twice with $75 \%$ ethanol and finally resuspended in $20 \mu \mathrm{L}$ of Tris $20 \mathrm{mM}$-DEPC. Total RNA concentration and purity were estimated in a NanoDrop ${ }^{\mathrm{TM}}$ One/OneC Microvolume UV-Vis Spectrophotometer (ThermoFisher Scientific) and the integrity was evaluated in a 2100 Bioanalyzer using an Agilent RNA 6000 Pico chip. After DNase treatment, the samples were subjected to PCR to verify the absence of DNA contamination. cDNA synthesis was performed with $1 \mu \mathrm{g}$ of the RNA and Thermo Scientific $\mathrm{H}$ Minus First Strand cDNA Synthesis kit. cDNA synthesis was verified by PCR and electrophoresis.

Amplification efficiency of the primers used in the RT-qPCR were verified using $300 \mathrm{nM}$ of each primer and a 2-fold dilution series of the cDNA to generate a standard curve composed of 4 concentrations as follows: $62.5,31.25,15.625$, and $7.8125 \mathrm{ng} / \mu \mathrm{L}$. Each dilution reaction was performed in triplicate using the Maxima SYBR Green/ROX qPCR Master Mix kit (ThermoFisher Scientific) following the manufacturer instructions in a QuantStudio 3 equipment (ThermoFisher Scientific). Primers for the normalizing gene rps $J$ 
276

277

278

279

280

281

282

283

284

285

286

287

288

289

(F_rpsJ 5' TGAAACGGCTAAGCGTTCTG 3', R_rpsJ 5' ACGCATCTCGAATTGCTCAC $3^{\prime}$ ), and for the nitrilases cynD (F_cynD 5' TGCCCAAAATGAGCAGGTAC 3', R_cynD 5' AAATGTCTGTGTCGCGATGG 3') and ykrU (F_ykrU 5' TTGGTGCGATGATTTGCTAT 3', R_ykrU 5' GTGTCTCTGCTTGTGCCTGT 3') were tested for efficiency. The amplification efficiency of the GPCR reaction was calculated through the slope of the cDNA curve obtained for each primer pair.

Since primer pairs have showed similar efficiency, $(y k r U=119.108 \%, c y n D=108.385 \%$, $r p s J=104.55 \%$ ), we performed each qPCR assay in technical triplicates using 15.625 $\mathrm{ng} / \mathrm{\mu L}$ of cDNA and the kit Maxima SYBR Green/ROX qPCR Master Mix (ThermoFisher Scientific) in a QuantStudio 3 equipment (ThermoFisher Scientific). $\triangle \triangle C T$ values were calculated in absence or presence of cyanide for the nitrilase genes ykrU and cynD using rpsJ as the normalizing gene. Three biological replicates were performed.

\section{RESULTS AND DISCUSSION}

\section{Three Bacillus spp. isolates with capacity of cyanide degradation}

Several colonies were obtained after selective enrichment in cyanide containing media of water in contact with mine tailing from a river near Casapalca and La Oroya mines located in San Mateo de Huanchor, Lima - Peru. Twenty colonies were screened for the ability to degrade cyanide (Table S2) and three colonies with the greatest efficiency in cyanide degradation (isolates 8, 12, and 17) were selected for further studies (Table S2).

Sequencing of the V6, V7, and V8 variable regions of $16 \mathrm{~S}$ rRNA gene of the three selected isolates and analysis by BLAST showed that they belong to the genus Bacillus (Table S3). Isolates 12 and 17 were identified as Bacillus licheniformis and Bacillus subtilis, respectively (Table S3) and were named Bacillus licheniformis PER-URP-12 and Bacillus subtilis PER-URP-17. Isolate 8 was classified as a member of the Bacillus pumilus group based on the 16S rRNA gene sequence (Table S3). However it was not possible to discriminate among the different species in the Bacillus pumilus group (Liu et al., 2013) and as such this isolated was provisionally named Bacillus sp. PER-URP-08.

The three strains were then sequenced in order to obtain a more accurate taxonomical classification as well as to gain insights about possible routes of cyanide degradation in the three strains under study. Table S4 shows a summary of assembly and annotation metrics of these genomes.

\section{Bacillus sp. PER-URP-08 is classified as Bacillus safensis based on core-genome comparisons}

We performed a genome-wide comparative analysis of Bacillus sp. PER-URP-08 with 132 genomes of species from the Bacillus pumilus group retrieved from the GenBank/NCBI database (Benson et al., 2013) and identified 1766 coding sequences present in all the genomes (core genes). An identity matrix based on an alignment of these core genes showed three well defined branches and two genomes that do not belong to any of these three branches (Fig. 1A).

Branch 1 (Fig. 1A, brown names) contains several strains already characterized as Bacillus altitudinis by different methods (for instance: BA06, ku-bf1, B-388 (X. Fu et al., 2021)) and also 4 strains (TUAT1, MTCB 6033, SH-B11 and C4) previously annotated as Bacillus pumilus. However, our analysis clearly demonstrates that they belong to Bacillus altitudinis and therefore require reclassification (Table S5) as previously suggested 
321

322

323

324

325

326

327

328

329

330

331

332

333

334

335

336

337

338

339

340

341

342

343

344

345

346

347

348

349

350

351

352

353

354

355

356

357

358

359

360

361

362

363

364

365

366

367

(Espariz et al., 2016; X. Fu et al., 2021). The core genes within the Bacillus altitudinis branch share more than 0.98 identity whereas they share less than 0.895 identity with core genomes of the other two branches (Fig. 1B).

Identity of core genes in branch 2 is greater than 0.96 , and this branch is more related to branch 3 (Bacillus pumilus, see below) than to branch 1 (Bacillus altitudinis) (Fig. 1C). Branch 2 (Fig. 1A, green names) contains the Bacillus safensis type strain FO-36b (Satomi et al., 2006) as well as other strains already classified as Bacillus safensis such as B4107, B4134, and B4129 (Espariz et al., 2016). Bacillus sp. PER-URP-08 appeared inside this branch very near to the type strain FO-36b (99.2\% identity) (Fig. 1A) and so will be named Bacillus safensis PER-URP-08 from here on.

Branch 3 (Fig. 1A, blue names) contains the SAFR-032 strain that was the first completely sequenced genome of Bacillus pumilus (Gioia et al., 2007; Stepanov et al., 2016). This branch 3 appears to be more heterogeneous than the other two branches (Bacillus altitudinis and Bacillus safensis) with more than 0.95 identity of the core genes of this branch (Fig. 1D). Additionally, two genomes isolated from Mexico (CH144a_4T and 145) share less than 0.95 identity with the branch 3 and even less with branches 1 and 2 (Fig. $1 \mathrm{E})$. The fact that these two genomes share less than 0.95 identity with all the other genomes in the analysis (Fig. 1E) indicates that CH144a_4T and 145 strains should be classified as different species outside the Bacillus pumilus group.

\section{A cyanide dihydratase is likely the responsible for cyanide degradation in $B$. safensis PER-URP-08}

To gain insight regarding the enzymes responsible for cyanide metabolism in the strains $B$. safensis PER-URP-08, B. licheniformis PER-URP-12, and B. subtilis PER-URP-17, we first searched for genes coding for proteins related to nitrilases. The PFAM database annotates homologs of nitrilases as CN_hydrolases under the PFAM code PF00795. Using IMG/M system tools (Chen et al., 2021), we determined the presence of three, two, and two proteins containing $\mathrm{CN}$ hydrolase domains in $B$. safensis PER-URP-08, $B$. licheniformis PER-URP-12, and B. subtilis PER-URP-17, respectively (Fig. S1). Both $B$. licheniformis PER-URP-12 and $B$. subtilis PER-URP-17 present the genes yhcX (NCBI locus tags: EGI08_RS06285 and EGI09_16505, respectively) and mtnU (EGI08_RS08970 and EGI09_01680, respectively). YhcX is probably involved in the degradation of indole-3acetonitrile, a sub product of tryptophan metabolism (Idris et al., 2007) (Fig. S1). On the other hand, MtnU has been described as a possible enzyme catalyzing the conversion of alpha-ketoglutaramate to alpha-ketoglutarate involved in the metabolism of methionine (Ellens et al., 2015; Sekowska \& Danchin, 2002) (Fig. S1). None of the enzymes with a CN_hydrolase domain in B. licheniformis PER-URP-12 and B. subtilis PER-URP-17 appears to be responsible for cyanide degradation. However, apart from these proteins, Bacillus and other genera present proteins with rhodanese domains (PFAM codes PF12368 and PF00581) (Table S6) that are able to convert cyanide to thiocyanate (Cipollone et al., 2006; Itakorode et al., 2019). Thus, it is likely that those rhodanese enzymes are responsible for the degradation of cyanide by $B$. licheniformis PER-URP-12 and $B$. subtilis PER-URP-17. Further studies are necessary to test this hypothesis.

B. safensis PER-URP-08 presents yhcX (EGI07_01665) but not $m t n U$. In addition, this strain carries two other proteins containing a CN_hydrolase domain, EGI07_17510 and CynD (EGI07_08135). EGI07_17510 is a protein of unknown function whereas CynD homologs (Fig. S2) hydrolyzes cyanide to produce ammonia and formic acid (Dash et al., 2009; Ibrahim et al., 2015). We therefore carried out a series of experiments to test the 
368

369

hypothesis that CynD is the enzyme responsible for cyanide degradation in $B$. safensis PER-URP-08.

\section{C-terminal residues differentiate CynD from B. pumilus and B. safensis}

We first constructed a maximum likelihood (ML) phylogenetic tree based on the 132 core genomes of strains from Bacillus pumilus group (Fig. 2A) and searched for orthologs of CynD in the strains present in the ML tree (see Methods for details of the search). The ML tree confirmed the three branches identified above (Fig. 1A) and that two genomes (CH144a_4T and 145) do not belong to any of these branches (Fig. 2A). Intriguingly, CynD-encoding sequences were found in some representatives of $B$. pumilus (44 out of 56 ) and $B$. safensis (19 out of 23) but not in B. altitudinis. Three monophyletic B. pumilus and one monophyletic $B$. safensis clades lack CynD (Fig. 2A). This could be due to processes of gene gain and/or loss in the strains, and further studies are necessary to distinguish between these or other possibilities. It is also possible that some cynD genes were no sequenced in some incomplete genomes.

Next, we identified twenty-three different sequences of CynD in the 132 genomes (Table S7) and a ML phylogenetic tree based on aminoacid sequences was constructed, including the sequences of the CynD from strain $C 1\left(C_{n n D}\right)$ (accession id: AAN77004.1) and of the CynD from B. safensis PER-URP-08 (CynD PER-URP-08). A clear separation between CynD from $B$. safensis and from $B$. pumilus could be observed in the $\mathrm{ML}$ tree (Fig. 2B). Interestingly, $\mathrm{CynD}_{\mathrm{C} 1}$ appear more related to the B. safensis group (Fig. 2B). Due to the several taxonomic misclassifications of strains belonging to the Bacillus pumilus group (as reported here and by others (Espariz et al., 2016; X. Fu et al., 2021; Liu et al., 2013)), it is likely that strain $C 1$ truly belongs to a $B$. safensis species; however, complete genome of $\mathrm{C} 1$ is not available to confirm this hypothesis.

The most variable region in the nitrilase protein family is the C-terminal (Benedik \& Sewell, 2018; Thuku et al., 2009). Thus, we associated a phylogenetic tree obtained from the fulllength sequences of identified CynDs homologs to an alignment of the C-terminal region (residues 296 to 330) (Fig. 2B). Residues F314, D318, H323 in B. safensis CynD are L314, A318, and N323 in the B. pumilus protein. Other residues can vary in one of the species but are strictly conserved in the other, for instance, residues Q309 and I325 in B. safensis are T309 or N309 and M325 or L325 in B. pumilus. Residue 308 can be P or M in $B$. safensis but is strictly $D$ in $B$. pumilus (Fig. $2 \mathrm{~B}$ ). $\mathrm{CynD}_{\mathrm{C} 1}$ has the aminoacids strictly conserved in $B$. safensis supporting the conclusion that $C 1$ belongs to $B$. safensis species. Furthermore, residue 27, outside the $C$-terminal, is $E$ in $B$. safensis and strain $C 1$ but $Q$ in B. pumilus.

\section{CynD from B. safensis PER-URP-08 it is still active at pH 9.}

We then went on to characterize some biochemical properties of CynD PER-URP-08. First, we cloned and expressed recombinant CynD $\mathrm{PER}_{\text {-URP-08 }}$ in E. coli and determined the basic kinetic constants of the purified recombinant enzyme. Although CynDs are known to be able to adopt different oligomeric states, no evidence of cooperativity was observed in our enzymatic assays (Fig. 3A). Instead, a simple Michaelis-Menten model fit the experimental data adequately. $\mathrm{K}_{\mathrm{m}}$ and $\mathrm{k}_{\text {cat }}$ estimated using this model were $1.93 \mathrm{mM}$ and $6.85 \mathrm{~s}^{-1}$ (Fig. $3 A$, S3). The $K_{m}$ value is similar to that previously reported for $C_{y n D_{C 1}}$ and from other species (2.56 mM to $7.3 \mathrm{mM}$ ) similar but $\mathrm{k}_{\text {cat }}$ is lower $\left(433 \mathrm{~s}^{-1}\right.$ to $\left.61600 \mathrm{~s}^{-1}\right)$ (Crum et al., 2015; Crum et al., 2016; Jandhyala et al., 2005; Vargas-Serna et al., 2020). 
414

Due to the volatility of hydrogen cyanide in its protonated $\mathrm{HCN}$ state and its pKa of 9.2 (Brüger et al., 2018), bioremediation processes should preferably be carried out at or above $\mathrm{pH}$ 9. To test if $\mathrm{CynD}_{\mathrm{PER}-U \mathrm{RP}-08}$ is active at $\mathrm{pHs}$ greater than 8 , we tested its activity at $\mathrm{pH}$ 9, 10, and 11. Figure 3B shows that recombinant $C_{\text {nnDER-URP-08 }}$ carrying a Cterminal $6 \mathrm{x}$-His tag is active up to $\mathrm{pH} 9$ and inactive at $\mathrm{pH} 10$ and 11. Other wild-type CynDs have been shown to be active only up to pH 8 (Crum et al., 2016; Jandhyala et al., 2005) and $\mathrm{CynD}_{\mathrm{C} 1}$ with C-terminal $6 \mathrm{x}$-His tag had its activity compromised at $\mathrm{pH} 9$ (Vargas-Serna et al., 2020). The $\mathrm{CynD}_{\mathrm{C} 1}$ and $\mathrm{CynD}_{\text {PER-URP-08 }}$ sequences only differ at five positions: are I18V, S25T, E155D, H305Q and N307Y (first letter correspond to $\mathrm{CynD}_{\mathrm{C} 1}$ ) with the last two substitutions H305Q and N307Y near the C-terminus.

Other studies were able to generate active versions of CynD active at $\mathrm{pH} 9$ by introducing mutations in some conserved positions (K93R; Q86R, E96G, D254G) or by replacing the C-terminal from CynD $_{\mathrm{C} 1}$ with the C-terminal from CynD from Pseudomonas stutzeri (Crum et al., 2015; Wang et al., 2012) (note that wild-type CynD from $P$. stutzeri has not been tested at $\mathrm{pH}$ 9).

\section{Alkaline $\mathrm{pH}$ reduces the degree of oligomerization of CynD $_{\mathrm{PER}-\mathrm{URP}-08}$}

The oligomerization state of nitrilases have been associated with enzyme activity and stability (Crum et al., 2015; Crum et al., 2015; Crum et al., 2016; Martínková et al., 2015; Park et al., 2016; Wang et al., 2012). In the case of CynDs of $\mathrm{CynD}_{\mathrm{C} 1}$ and CynD from $P$. stutzeri, mutations in the C-terminal region decrease oligomerization (M. Crum et al., 2016; M. A. N. Crum et al., 2015; Wang et al., 2012). The C-terminal of nitrilases stabilizes the spiral structure through crisscrossed beta sheets in the center of the oligomer (Mulelu et al., 2019; Thuku et al., 2009). Also, pH has been shown to promote higher order oligomerization states of CynDs (D. Jandhyala et al., 2003; Wang et al., 2012); however, the effects of $\mathrm{pH}$ greater than 9 have not been reported.

Since, CynD PER-URP-08 has differences in C-terminal with respect to other CynDs we used

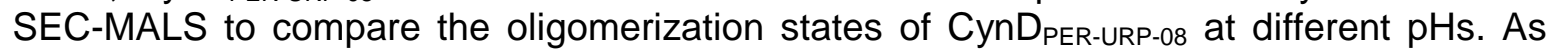
expected, pHs higher than 8 results in smaller sized oligomers. At pH 11 the monomer $(38.5 \mathrm{kDa})$ is the predominant species (Fig. 4A), whereas $\mathrm{pH} 10$ and 9 presented oligomeric states ranging from $\sim 3$-mer to $\sim 5$-mer $(\mathrm{pH} \mathrm{10,100.85} \mathrm{to} 176.34 \mathrm{kDa})$ and $\sim 4$ mer to 6-mer (pH 9, 133.19 to $226.99 \mathrm{kDa}$ ) (Fig. 4B-C). Furthermore, CynD PER-URP-08 presented oligomers ranging from $\sim 24$-mer to $\sim 48$-mer (918.31 to $1851.39 \mathrm{kDa})$ at $\mathrm{pH} 8$ (Fig. 4D) in contrast to what was reported for $\mathrm{CynD}_{\mathrm{C} 1}$ at $\mathrm{pH} 8$ which forms an 18-mer spiral (D. Jandhyala et al., 2003). These differences could be a result of the differences in aminoacid sequence between CynD $\mathrm{PER}_{\text {-URP-08 }}$ and $\mathrm{CynD}_{\mathrm{C} 1}$ or due to the presence of the Cterminal $6 x-H$ is tag in CynD PER-URP-08. Experiments with $C_{y n D_{C 1}}$ were carried out with untagged protein or with protein carrying an N-terminal 6x-His tag (Crum et al., 2015; Jandhyala et al., 2003; Park et al., 2016; Wang et al., 2012). Electron micrographs of negatively stained CynD PER-URP-08 at $\mathrm{pH} 8$ showed spirals of different sizes supporting the conclusion that $\mathrm{CynD}_{\mathrm{PER}-U R \mathrm{R}-08}$ at this $\mathrm{pH}$ is adopts a range of different oligomerization states (Fig. 4E).

\section{Expression of CynD $\mathrm{D}_{\mathrm{PER}-\mathrm{URP}-08}$ from $B$. safensis PER-URP-08 is induced in the presence of cyanide}

Some previous studies have considered the possibility that CynD gene expression is regulated by cyanide, but this point remains unclear (D. Jandhyala et al., 2003). To address this question, we exposed $B$. safensis PER-URP-08 to $100 \mathrm{ppm} \mathrm{CN}^{-}$(in the form 
462

463

464

465

466

467

468

469

470

471

472

473

474

475

476

477

478

479

480

481

482

483

484

485

486

487

488

489

490

491

492

493

494

495

496

497

498

499

500

501

502

503

504

505

506

507

508

of $38.5 \mathrm{mM} \mathrm{NaCN}$ ) at $30^{\circ} \mathrm{C}$ for $4 \mathrm{~h}$ without agitation and the mRNA levels of $c y n D$ were measured and compared with the levels observed in cells grown in the absence of $\mathrm{CN}^{-}$.

We observed a 6.7-fold increase in expression of $c y n D$ in the presence of cyanide (Fig. 5). To evaluate if this overexpression is specific for $c y n D$ nitrilase and not to other nitrilases of B. safensis PER-URP-08, we also measured the mRNA levels of $y \mathrm{krU}$ that also possesses a CN_hydrolase domain. We did not observe differences in $y k r U$ expression in the presence and absence of cyanide. To our knowledge, this is the first report showing induction in the expression of $c y n D$ in the presence of cyanide. This could possibly be a physiological response of the bacteria in order to protect itself from the toxic effects of the compound, but further studies are necessary to more fully understand the molecular mechanisms behind this response.

\section{CONCLUSIONS}

Here we report the isolation and the genome sequences of three cyanide-degrading Bacillus strains obtained from water in contact with mine tailings in Lima - Peru. They were phylogenetically classified and named Bacillus licheniformis PER-URP-12, Bacillus subtilis PER-URP-17 and Bacillus safensis PER-URP-08. Comparative genomic analyses indicate that some strains currently classified as B. pumilus with publicly available genomes should be reclassified as Bacillus altitudinis (strains TUAT1, MTCB 6033, SH$\mathrm{B} 11$, and $\mathrm{C} 4$ ). Furthermore, we propose that strains $\mathrm{CH} 144 \mathrm{a}$ 4T and 145 should be classified belonging a new species distinct from B. pumilus, B.safensis, or B. altitudinis.

We propose that in $B$. licheniformis PER-URP-12 and $B$. subtilis PER-URP-17 rhodaneses (table S6) are possibly the enzymes that confer cyanide degradation capabilities to these strains. In the case of $B$. safensis PER-URP-08, we suggest that EGI07_08135 codes for an ortholog of cyanide dihydratase $\mathrm{CynD}$ that imparts the cyanide-degradation ability to this strain.

We found that while no $B$. altitudinis strains code for CynD orthologs, some B. pumilus and $B$. safensis strains present $\mathrm{CynD}$ orthologous sequences. CynD from B. pumilus and $B$. safensis have high identity (>97\%), however conserved differences in the C-terminus allow us to differentiate between CynD from $B$. safensis or $B$. pumilus (at least in the analyzed genomes). Additionally, sequence analysis of the previously described CynD from strain $C 1\left(C_{1} D_{C 1}\right)$, named as $B$. pumilus $C y n D$ in the literature, is more closely related to CynDs from $B$. safensis than from $B$. pumilus. Thus, indicating that $\mathrm{CynD}_{\mathrm{C} 1}$ is a representative of $B$. pumilus CynDs.

We characterized some aspects of CynD from B. safensis PER-URP-08 (CynD PER-URP-08) corroborating what was described for CynDs from other species and adding new knowledge about these enzymes. First, enzymatic assays with CynD $\mathrm{PER}_{\text {-URP-08 }}$ found no evidence of cooperativity despite the known oligomerization patterns of these enzymes. Second, $\mathrm{K}_{\mathrm{m}}$ and $\mathrm{K}_{\text {cat }}$ of CynD PER-URP-08 were $1.93 \mathrm{mM}$ and $6.65 \mathrm{~s}^{-1}$, respectively. Third, despite that $C_{\text {SnnDER-URP-08 }}$ and $\mathrm{CynD}_{\mathrm{C} 1}$ only differ in five positions, CynD $\mathrm{DER}_{\text {PERP-08 }}$ retain almost the same activity in $\mathrm{pH} 9$ whereas $\mathrm{CynD}_{\mathrm{C1}}$ has been reported as almost inactive at this $\mathrm{pH}$. Fourth, as $\mathrm{pH}$ is known to influence the oligomerization of CynDs, we reported that in $\mathrm{pH} 8$, CynD $_{\text {PER-URP-08 }}$ forms spirals made up of an estimated $\sim 24$ to $\sim 48$ subunits showing that several oligomeric states are present in this $\mathrm{pH}$. This is different compared with $\mathrm{CynD}_{\mathrm{C} 1}$ that was reported to forms just oligomers of 18 subunits at this $\mathrm{pH}$. Moreover, at $\mathrm{pH} 11$, the CynD PER-URP-08 monomer was observed. Finally, we showed for the first time,

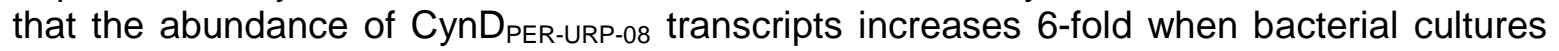
are exposed to $\mathrm{CN}^{-}$. 
509

510

\section{1}

512

513

514

515

516

517

518

519

520

521

522

523

524

525

526

527

528

529

530

531

532

533

534

535

536

537

538

539

540

541

542

543

544

545

546

547

548

549

550

Altogether, the results we reported here warrant further investigation to explore the

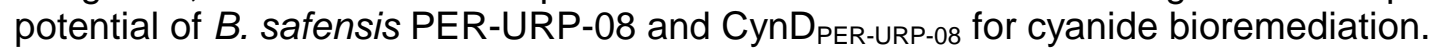

\section{DATA AVAILABILITY}

The final genomes assemblies are available in IMG/M (Chen et al., 2021) and GenBank/NCBI (Benson et al., 2013) databases under the accessions numbers: 2818991268, 2818991267, 2818991266 and RSEW00000000.1, RSEY00000000.1, RSEX0000000.1, respectively for Bacillus safensis PER-URP-08, Bacillus licheniformis PER-URP-12, Bacillus subtilis PER-URP-17.

\section{REFERENCES}

Akinpelu, E. A., Adetunji, A. T., Ntwampe, S. K. O., Nchu, F., \& Mekuto, L. (2018). Performance of fusarium oxysporum EKT01/02 isolate in cyanide biodegradation system. Environmental Engineering Research, 23(2), 223-227. https://doi.org/10.4491/eer.2017.154

Al-Badri, B. A. S., Al-Maawali, S. S., Al-Balushi, Z. M., Al-Mahmooli, I. H., Al-Sadi, A. M., \& Velazhahan, R. (2020). Cyanide degradation and antagonistic potential of endophytic Bacillus subtilis strain BEB1 from Bougainvillea spectabilis Willd. All Life, 13(1), 9298. https://doi.org/10.1080/26895293.2020.1728393

Altschul, S. F., Gish, W., Miller, W., Myers, E. W., \& Lipman, D. J. (1990). Basic local alignment search tool. Journal of Molecular Biology, 215(3), 403-410. https://doi.org/10.1016/S0022-2836(05)80360-2

Benedik, M. J., \& Sewell, B. T. (2018). Cyanide-degrading nitrilases in nature. Journal of General and Applied Microbiology, 64(2), 90-93. https://doi.org/10.2323/jgam.2017.06.002

Benson, D. A., Cavanaugh, M., Clark, K., Karsch-Mizrachi, I., Lipman, D. J., Ostell, J., \& Sayers, E. W. (2013). GenBank. Nucleic Acids Research, 41(D1), 36-42. https://doi.org/10.1093/nar/gks1195

Bosi, E., Donati, B., Galardini, M., Brunetti, S., Sagot, M. F., Lió, P., Crescenzi, P., Fani, R., \& Fondi, M. (2015). MeDuSa: A multi-draft based scaffolder. Bioinformatics, 31(15), 2443-2451. https://doi.org/10.1093/bioinformatics/btv171

Brüger, A., Fafilek, G., Restrepo B., O. J., \& Rojas-Mendoza, L. (2018). On the volatilisation and decomposition of cyanide contaminations from gold mining. Science of the Total Environment, 627, 1167-1173. https://doi.org/10.1016/j.scitotenv.2018.01.320

Castric, P. A., \& Strobel, G. A. (1969). Cyanide metabolism by Bacillus megaterium. Journal of Biological Chemistry, 244(15), 4089-4094. https://doi.org/10.1016/s00219258(17)36388-3

Chen, I. M. A., Chu, K., Palaniappan, K., Ratner, A., Huang, J., Huntemann, M., Hajek, P., Ritter, S., Varghese, N., Seshadri, R., Roux, S., Woyke, T., Eloe-Fadrosh, E. A., Ivanova, N. N., \& Kyrpides, N. C. (2021). The IMG/M data management and analysis system v.6.0: New tools and advanced capabilities. Nucleic Acids Research, 49(D1), 
552

553

554

555

556

557

558

559

560

561

562

563

564

565

566

567

568

569

570

571

572

573

574

575

576

577

578

579

580

581

582

583

584

585

586

587

588

589

590

591

592

593
Cipollone, R., Ascenzi, P., Frangipani, E., \& Visca, P. (2006). Cyanide detoxification by recombinant bacterial rhodanese. Chemosphere, 63(6), 942-949. https://doi.org/10.1016/j.chemosphere.2005.09.048

Cock, P. J. A., Antao, T., Chang, J. T., Chapman, B. A., Cox, C. J., Dalke, A., Friedberg, I., Hamelryck, T., Kauff, F., Wilczynski, B., \& De Hoon, M. J. L. (2009). Biopython: Freely available Python tools for computational molecular biology and bioinformatics. Bioinformatics, 25(11), 1422-1423. https://doi.org/10.1093/bioinformatics/btp163

Coil, D., Jospin, G., \& Darling, A. E. (2015). A5-miseq: An updated pipeline to assemble microbial genomes from Illumina MiSeq data. Bioinformatics, 31(4), 587-589. https://doi.org/10.1093/bioinformatics/btu661

Crum, M. A., Park, J. M., Mulelu, A. E., Sewell, B. T., \& Benedik, M. J. (2015). Probing Cterminal interactions of the Pseudomonas stutzeri cyanide-degrading CynD protein. Applied Microbiology and Biotechnology, 99(7), 3093-3102. https://doi.org/10.1007/s00253-014-6335-x

Crum, M. A., Park, J. M., Sewell, B. T., \& Benedik, M. J. (2015). C-terminal hybrid mutant of Bacillus pumilus cyanide dihydratase dramatically enhances thermal stability and $\mathrm{pH}$ tolerance by reinforcing oligomerization. Journal of Applied Microbiology, 118(4), 881-889. https://doi.org/10.1111/jam.12754

Crum, M. A., Trevor, B., \& Benedik, M. (2016). Bacillus pumilus cyanide dihydratase mutants with higher catalytic activity. Frontiers in Microbiology, 7(AUG), 1-10. https://doi.org/10.3389/fmicb.2016.01264

Dash, R. R., Gaur, A., \& Balomajumder, C. (2009). Cyanide in industrial wastewaters and its removal: A review on biotreatment. Journal of Hazardous Materials, 163(1), 1-11. https://doi.org/10.1016/j.jhazmat.2008.06.051

Dumestre, A., Chone, T., Portal, J. M., Gerard, M., \& Berthelin, J. (1997). Cyanide degradation under alkaline conditions by a strain of Fusarium solani isolated from contaminated soils. Applied and Environmental Microbiology, 63(7), 2729-2734. https://doi.org/10.1128/aem.63.7.2729-2734.1997

Ellens, K. W., Richardson, L. G. L., Frelin, O., Collins, J., Ribeiro, C. L., Hsieh, Y. F., Mullen, R. T., \& Hanson, A. D. (2015). Evidence that glutamine transaminase and omega-amidase potentially act in tandem to close the methionine salvage cycle in bacteria and plants. Phytochemistry, 113, 160-169. https://doi.org/10.1016/j.phytochem.2014.04.012

Espariz, M., Zuljan, F. A., Esteban, L., \& Magni, C. (2016). Taxonomic identity resolution of highly phylogenetically related strains and selection of phylogenetic markers by using genome-scale methods: The bacillus pumilus group case. PLOS ONE, 11(9), 1-17. https://doi.org/10.1371/journal.pone.0163098

Fry, W. E., \& Millar, R. L. (1972). Cyanide degradion by an enzyme from Stemphylium loti. Archives of Biochemistry and Biophysics, 151(2), 468-474. https://doi.org/10.1016/0003-9861(72)90523-1

Fu, L., Niu, B., Zhu, Z., Wu, S., \& Li, W. (2012). CD-HIT: Accelerated for clustering the next-generation sequencing data. Bioinformatics, 28(23), 3150-3152. 
https://doi.org/10.1093/bioinformatics/bts565

595

596

597

598

599

600

601

602

603

604

605

606

607

608

609

610

611

612

613

614

615

616

617

618

619

620

621

622

623

624

625

626

627

628

629

630

631

632

633

634

635

636

Fu, X., Gong, L., Liu, Y., Lai, Q., Li, G., \& Shao, Z. (2021). Bacillus pumilus Group Comparative Genomics: Toward Pangenome Features, Diversity, and Marine Environmental Adaptation. Frontiers in Microbiology, 12(May), 1-16. https://doi.org/10.3389/fmicb.2021.571212

Gioia, J., Yerrapragada, S., Qin, X., Jiang, H., Igboeli, O. C., Muzny, D., Dugan-Rocha, S., Ding, Y., Hawes, A., Liu, W., Perez, L., Kovar, C., Dinh, H., Lee, S., Nazareth, L., Blyth, P., Holder, M., Buhay, C., Tirumalai, M. R., ... Weinstock, G. M. (2007). Paradoxical DNA repair and peroxide resistance gene conservation in Bacillus pumilus SAFR-032. PLoS ONE, 2(9). https://doi.org/10.1371/journal.pone.0000928

Hendry-Hofer, T. B., Ng, P. C., Witeof, A. E., Mahon, S. B., Brenner, M., Boss, G. R., \& Bebarta, V. S. (2019). A Review on Ingested Cyanide: Risks, Clinical Presentation, Diagnostics, and Treatment Challenges. Journal of Medical Toxicology, 15(2), 128133. https://doi.org/10.1007/s13181-018-0688-y

Hoang, D. T., Chernomor, O., Von Haeseler, A., Minh, B. Q., \& Vinh, L. S. (2018). UFBoot2: Improving the ultrafast bootstrap approximation. Molecular Biology and Evolution, 35(2), 518-522. https://doi.org/10.1093/molbev/msx281

Ibrahim, K. K., Syed, M. A., Shukor, M. Y., \& Ahmad, S. A. (2015). Biological remediation of cyanide: A review. Biotropia, 22(2), 151-163. https://doi.org/10.11598/btb.2015.22.2.393

Idris, E. S. E., Iglesias, D. J., Talon, M., \& Borriss, R. (2007). Tryptophan-dependent production of Indole-3-Acetic Acid (IAA) affects level of plant growth promotion by Bacillus amyloliquefaciens FZB42. Molecular Plant-Microbe Interactions, 20(6), 619626. https://doi.org/10.1094/MPMI-20-6-0619

Ingvorsen, K., Hojer-Pedersen, B., \& Godtfredsen, S. E. (1991). Novel cyanide-hydrolyzing enzyme from Alcaligenes xylosoxidans subsp. denitrificans. Applied and Environmental Microbiology, 57(6), 1783-1789. https://doi.org/10.1128/aem.57.6.1783-1789.1991

Itakorode, B., Okonji, R., Adedeji, O., Torimiro, O., Famakinwa, T., \& Chukwuejim, C. (2019). Isolation, screening and optimization of Bacillus cereus for a thiosuphate sulphur transferase production. Journal of Chemical and Pharmaceutical Sciences, 12(03), 79-84. https://doi.org/10.30558/jchps.20191203003

Jandhyala, D., Berman, M., Meyers, P. R., Sewell, B. T., Willson, R. C., \& Benedik, M. J. (2003). CynD, the cyanide dihydratase from Bacillus pumilus: Gene cloning and structural studies. Applied and Environmental Microbiology, 69(8), 4794-4805. https://doi.org/10.1128/AEM.69.8.4794-4805.2003

Jandhyala, D. M., Willson, R. C., Sewell, B. T., \& Benedik, M. J. (2005). Comparison of cyanide-degrading nitrilases. Applied Microbiology and Biotechnology, 68(3), 327335. https://doi.org/10.1007/s00253-005-1903-8

Javaheri Safa, Z., Aminzadeh, S., Zamani, M., \& Motallebi, M. (2017). Significant increase in cyanide degradation by Bacillus sp. M01 PTCC 1908 with response surface methodology optimization. AMB Express, 7(1). https://doi.org/10.1186/s13568-0170502-2 
637

638

639

640

641

642

643

644

645

646

647

648

649

650

651

652

653

654

655

656

657

658

659

660

661

662

663

664

665

666

667

668

669

670

671

672

673

674

675

676

677

678

679

Katoh, K., \& Standley, D. M. (2013). MAFFT multiple sequence alignment software version 7: Improvements in performance and usability. Molecular Biology and Evolution, 30(4), 772-780. https://doi.org/10.1093/molbev/mst010

Kosiol, C., \& Goldman, N. (2005). Different versions of the dayhoff rate matrix. Molecular Biology and Evolution, 22(2), 193-199. https://doi.org/10.1093/molbev/msi005

Kuyucak, N., \& Akcil, A. (2013). Cyanide and removal options from effluents in gold mining and metallurgical processes. Minerals Engineering, 50-51, 13-29. https://doi.org/10.1016/j.mineng.2013.05.027

Leavesley, H. B., Li, L., Prabhakaran, K., Borowitz, J. L., \& Isom, G. E. (2008). Interaction of cyanide and nitric oxide with cytochrome c oxidase: Implications for acute cyanide toxicity. Toxicological Sciences, 101(1), 101-111. https://doi.org/10.1093/toxsci/kfm254

Li, W., \& Godzik, A. (2006). Cd-hit: A fast program for clustering and comparing large sets of protein or nucleotide sequences. Bioinformatics, 22(13), 1658-1659. https://doi.org/10.1093/bioinformatics/btl158

Liu, Y., Lai, Q., Dong, C., Sun, F., Wang, L., Li, G., \& Shao, Z. (2013). Phylogenetic diversity of the Bacillus pumilus group and the marine ecotype revealed by multilocus sequence analysis. PLOS ONE, 8(11), 1-11. https://doi.org/10.1371/journal.pone.0080097

Martínková, L., Veselá, A. B., Rinágelová, A., \& Chmátal, M. (2015). Cyanide hydratases and cyanide dihydratases: emerging tools in the biodegradation and biodetection of cyanide. Applied Microbiology and Biotechnology, 99(21), 8875-8882. https://doi.org/10.1007/s00253-015-6899-0

Mekuto, L., Jackson, V. A., \& Obed Ntwampe, S. K. (2014). Biodegradation of Free Cyanide Using Bacillus Sp. Consortium Dominated by Bacillus Safensis, Lichenformis and Tequilensis Strains: A Bioprocess Supported Solely with Whey. Journal of Bioremediation \& Biodegradation, 05(02). https://doi.org/10.4172/2155-6199.s18-004

Meyers, P. R., Rawlings, D. E., Woods, D. R., \& Lindsey, G. G. (1993). Isolation and characterization of a cyanide dihydratase from Bacillus pumilus $\mathrm{C}$ 1. Journal of Bacteriology, 175(19), 6105-6112. https://doi.org/10.1128/jb.175.19.6105-6112.1993

Minh, B. Q., Schmidt, H. A., Chernomor, O., Schrempf, D., Woodhams, M. D., Von Haeseler, A., Lanfear, R., \& Teeling, E. (2020). IQ-TREE 2: New Models and Efficient Methods for Phylogenetic Inference in the Genomic Era. Molecular Biology and Evolution, 37(5), 1530-1534. https://doi.org/10.1093/molbev/msaa015

Mudder, T. I., Botz, M. M., \& Akçil, A. (2004). Cyanide and society: A critical review. The European Journal of Mineral Processing and Environmental Protection, 4(1), 62-74.

Mulelu, A. E., Kirykowicz, A. M., \& Woodward, J. D. (2019). Cryo-EM and directed evolution reveal how Arabidopsis nitrilase specificity is influenced by its quaternary structure. Communications Biology, 2(1), 1-11. https://doi.org/10.1038/s42003-0190505-4

Omura, H., Ikemoto, M., Kobayashi, M., Shimizu, S., Yoshida, T., \& Nagasawa, T. (2003). Purification, characterization and gene cloning of thermostable O-acetyl-Lhomoserine sulfhydrylase forming y-cyano-a-aminobutyric acid. Journal of Bioscience 

and Bioengineering, 96(1), 53-58. https://doi.org/10.1016/S1389-1723(03)90096-X

681

682

683

684

685

686

687

688

689

690

691

692

693

694

695

696

697

698

699

700

701

702
Pace, H. C., \& Brenner, C. (2001). The nitrilase superfamily: Classification, structure and function. Genome Biology, 2(1), 1-9. https://doi.org/10.1186/gb-2001-2-1reviews 0001

Park, J. M., Ponder, C. M., Sewell, B. T., \& Benedik, M. J. (2016). Residue Y70 of the nitrilase cyanide dihydratase from Bacillus pumilus is critical for formation and activity of the spiral oligomer. Journal of Microbiology and Biotechnology, 26(12), 2179-2183. https://doi.org/10.4014/jmb.1606.06035

Ping Wang; Hans D. VanEtten. (1992). Cloning and properties of a cyanide hydratase gene from the phytopathogenic fungus Gloeocercospora sorghi. Biochemical and Biophysical Research Communications, 187(2), 1048-1054. https://www.sciencedirect.com/science/article/abs/pii/0006291X92913038

Rinágelová, A., Kaplan, O., Veselá, A. B., Chmátal, M., Křenková, A., Plíhal, O., Pasquarelli, F., Cantarella, M., \& Martínková, L. (2014). Cyanide hydratase from Aspergillus niger K10: Overproduction in Escherichia coli, purification, characterization and use in continuous cyanide degradation. Process Biochemistry, 49(3), 445-450. https://doi.org/10.1016/j.procbio.2013.12.008

Satomi, M., La Duc, M. T., \& Venkateswaran, K. (2006). Bacillus safensis sp.nov., isolated from spacecraft and assembly-facility surfaces. International Journal of Systematic and Evolutionary Microbiology, 56(8), 1735-1740. https://doi.org/10.1099/ijs.0.641890

Sekowska, A., \& Danchin, A. (2002). The methionine salvage pathway in Bacillus subtilis. BMC Microbiology, 2, 1-14. https://doi.org/10.1186/1471-2180-2-8

Sexton, A. C., \& Howlett, B. J. (2000). Characterisation of a cyanide hydratase gene in the phytopathogenic fungus Leptosphaeria maculans. Molecular and General Genetics, 263(3), 463-470. https://doi.org/10.1007/s004380051190

Stepanov, V. G., Tirumalai, M. R., Montazari, S., Checinska, A., Venkateswaran, K., \& Fox, G. E. (2016). Bacillus pumilus SAFR-032 genome revisited: Sequence update and re-annotation. PLOS ONE, 11(6), 1-11. https://doi.org/10.1371/journal.pone.0157331

Tatusova, T., Dicuccio, M., Badretdin, A., Chetvernin, V., Nawrocki, E. P., Zaslavsky, L., Lomsadze, A., Pruitt, K. D., Borodovsky, M., \& Ostell, J. (2016). NCBI prokaryotic genome annotation pipeline. Nucleic Acids Research, 44(14), 6614-6624. https://doi.org/10.1093/nar/gkw569

Thuku, R. N., Brady, D., Benedik, M. J., \& Sewell, B. T. (2009). Microbial nitrilases: Versatile, spiral forming, industrial enzymes. Journal of Applied Microbiology, 106(3), 703-727. https://doi.org/10.1111/j.1365-2672.2008.03941.x

Vargas-Serna, C. L., Carmona-Orozco, M. L., \& Panay, A. J. (2020). Biodegradation of cyanide using recombinant Escherichia coli expressing Bacillus pumilus cyanide dihydratase. Revista Colombiana de Biotecnología, 22(1), 27-35. https://doi.org/10.15446/rev.colomb.biote.v22n1.79559

Wang, L., Watermeyer, J. M., Mulelu, A. E., Sewell, B. T., \& Benedik, M. J. (2012). Engineering $\mathrm{pH}$-tolerant mutants of a cyanide dihydratase. Applied Microbiology and 
Biotechnology, 94(1), 131-140. https://doi.org/10.1007/s00253-011-3620-9

724

725

726

727

728

729

730

731

732

733

734

Watanabe, A., Yano, K., Ikebukuro, K., \& Karube, I. (1998). Cloning and expression of a gene encoding cyanidase from Pseudomonas stutzeri AK61. Applied Microbiology and Biotechnology, 50(1), 93-97. https://doi.org/10.1007/s002530051261

Weisenfeld, N. I., Yin, S., Sharpe, T., Lau, B., Hegarty, R., Holmes, L., Sogoloff, B., Tabbaa, D., Williams, L., Russ, C., Nusbaum, C., Lander, E. S., Maccallum, I., \& Jaffe, D. B. (2014). Comprehensive variation discovery in single human genomes. Nature Genetics, 46(12), 1350-1355. https://doi.org/10.1038/ng.3121

Williams, H. J., \& Edwards, T. G. (1980). Estimation of cyanide with alkaline picrate. Journal of the Science of Food and Agriculture, 31(1), 15-22. https://doi.org/10.1002/jsfa.2740310104

\section{Acknowledgements}

We are very grateful to the Ricardo Palma University High-Performance Computational Cluster (URPHPC) managers Gustavo Adolfo Abarca Valdiviezo and Roxana Paola Mier Hermoza at the Ricardo Palma Informatic Department (OFICIC) for their contribution in programs and remote use configuration of URPHPC. We also thank Germán Sgro for help with negative staining.

\section{Funding Information}

Funding for this work was provided by São Paulo Research Foundation (FAPESP) student fellowship 2015/13318-4 to S.J.A and research grant 2017/17303-7 to C.S.F. The work was also supported by Coordination for the Improvement of Higher Education Personnel (CAPES) research grant 3385/2013 to A.M.D.S. P.M.P. received fellowships from CAPES (88882.160114/2017-1). C.S.F., and J.C.S., A.M.D.S. received research fellowship awards from the National Council for Scientific and Technological Development (CNPq). The funders had no role in study design, data collection and analysis, decision to publish, or preparation of the manuscript.

\section{Authors Contributions}

Conceptualization: S.J.A., A.G.S., A.M.D.S., Methodology: S.J.A., D.Z.S., A.C.P., M.B.R., C.M.P., L.F.M., P.M.P., C.M. Computing resources: M.Q.A., J.C.S., Data curation: S.J.A., D.Z.S., A.C.P., C.M.P. Formal analysis: S.J.A., D.S.Z., A.C.P., C.M.P., C.S.F. Visualization: S.J.A., D.Z.S. Writing - original draft preparation: S.J.A., Writing - review and editing: S.J.A., J.C.S., C.S.F., A.M.D.S. Supervision: S.J.A., A.G.S., M.Q.A., C.S.F., A.M.D.S. Funding acquisition: A.G.S., M.Q.A., C.S.F., J.C.S., A.M.D.S. All authors read, provided critical review, and approved the final manuscript.

\section{Conflicts of interest}

The authors declare that there are no conflicts of interest.

FIGURES:

Figure 1. Core genome identity matrix to classified genomes of Bacillus pumilus group genomes. A) An identity matrix of 132 core genomes of Bacillus pumilus group 
763

764

765

766

767

768

769

770

771

772

773

774

775

776

777

778

779

780

781

782

783

784

785

786

787

788

789

790

791

792

793

794

795

796

797

798

799

800

801

802

showing delimitations between three species: Bacillus altitudinis (brown names), Bacillus safensis (green names), Bacillus pumilus (blue names). Two core genomes (red names) appear outside of these three species. B - E) Plots showing the range of identity when compare $B$. altitudinis $(\mathrm{B}), B$. safensis $(\mathrm{C}), B$. pumilus $(\mathrm{D})$ or $B$. $s p(\mathrm{E})$ with itself or with other groups.

Figure 2. CynD is present in some genomes of $B$. pumilus and B. safensis and they are mainly differentiated by $\mathbf{C}$-terminal residues. A) Maximum likelihood tree of core genomes of 132 Bacillus pumilus group strains showing separation between three species. Color of the circles represent absence (green) or presence (blue) of CynD homologue in the genome. Circles with black and red borders represent complete genomes ("chromosome" or "complete" sequencing status in NCBI) and possibly not complete genomes ("scaffold" sequencing status in NCBI). B) Maximum likelihood tree of full-length CynD sequences associated to and alignment of their C-terminal region (residues 296 to 330). Showed in number blue or green are the positions that are completely conserved in Bacillus safensis or B. pumilus, respectively.

Figure 3. CynD $D_{\text {PER-URP-08 }}$ have similar kinetic constants to other CynD homologues and is still active up to $\mathrm{pH}$ 9. A) Plot of CynD concentration of cyanide adjusted to the Michaelis Menten equation. $\mathrm{Km}$ and Kcat constants calculated assuming this model are shown in the graphic. B) Percentage of cyanide removal in different $\mathrm{pHs}$ using different CynD $_{\mathrm{PER}-U \mathrm{RP}-08}$ concentrations. $\mathrm{CynD}_{\mathrm{PER}}$ URP-08 showed considerable activity in pH 8 and 9 but not in 10 and 11 .

Figure 4. SEC-MALS of $C_{\text {PER-URP-08 }}$ showed that higher pHs reduced its oligomerization states and TEM showed that $C_{\text {CynDE-URP-08 }}$ presents a helical structure. A-D) Plot of UV intensity/molar mass for CynD $\mathrm{DER}_{\mathrm{PRP}-08}$ in different $\mathrm{pHs}$. A pattern of decrease the oligomeric state while increasing the $\mathrm{pH}$ was observed. E) TEM micrographs at $\mathrm{pH} 8$ in two different magnifications (right and left) showed helical structures of CynD PER-URP-08.

Figure 5. $c y n D_{\text {PER-URP-08 }}$ but not $y k r U$ is induced in the presence of cyanide. Relative expression measured by RT-qPCR showed that when Bacillus safensis is in presence of cyanide the RNA levels of $c y n D$ are 6.67-fold greater than when in absence of cyanide. In contrast, other nitrilase gene ( $y k r U)$ have the same RNA levels in presence or absence of cyanide.

\section{SUPPLEMENTARY FIGURES}


803 Figure S1. Proteins containing CN_hydrolase domain in the three genomes studied.

804 Four CN_hydrolases containing-proteins were identified in the analyzed genomes. YkrU 805 and CynD are present only in $B$. safensis PER-URP-08. MtnU was found in $B$. 806 licheniformis PER-URP-12 and Bacillus subtilis PER-URP-17. YhcX was found in the three 807 genomes.

808 Figure S2. Alignments of identical protein group CynDs with CynD $_{\text {PER-URP-08 }}$ and

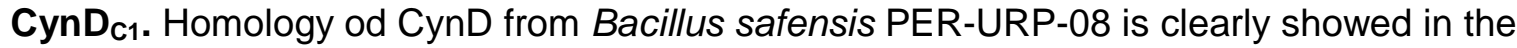
protein sequence alignments of several CynD homologs including those with tested enzymatic activity as CynD from B. pumilus strain $\mathrm{C} 1$.

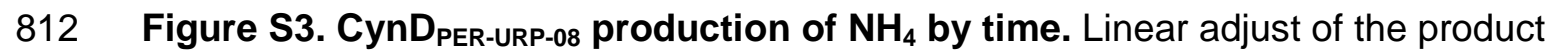
formation $\left(\mathrm{NH}_{4}\right)$ by CynD in the first 40 seconds of reaction using different initial

814 concentrations of cyanide.

\section{SUPLEMENTARY TABLES:}

817 Table S1. Accession numbers of reference genomes used in the assembly process.

818 Table S2. Cyanide removal percentage of the twenty isolates from mine tailings in 819 Peru.

820 Table S3. BLAST best-hits of the partial 16S rRNA gene for each tested strain.

821 Table S4. Summary of IMG/M annotations of the three Bacillus genomes.

822 Table S5. Summary information of the 132 genomes used in the core genomes 823 analysis.

824 Table S6. Rhodanese domain coding ORFs in the three sequenced genomes.

825 Table S7. Identical protein groups (IPG) NCBI accession IDs by strain and species. 


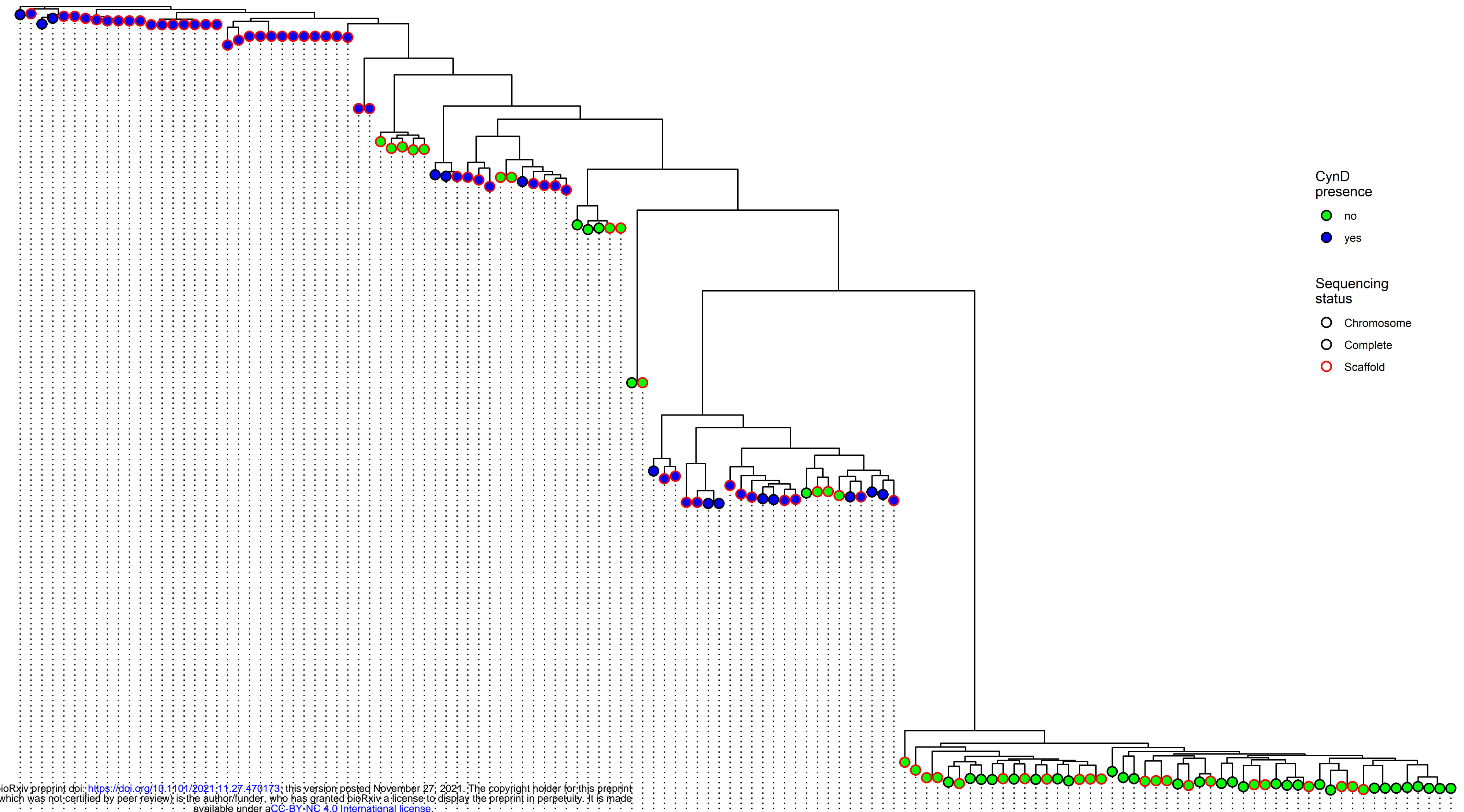

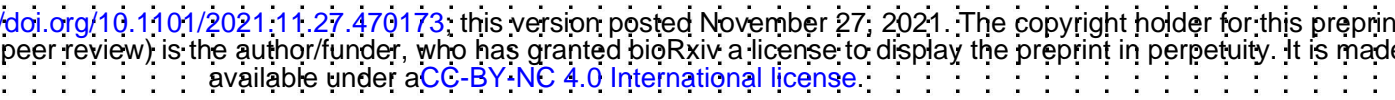

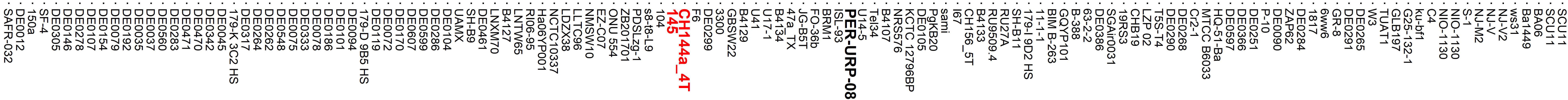

B. pumilus

B. safensis

B. altitudinis

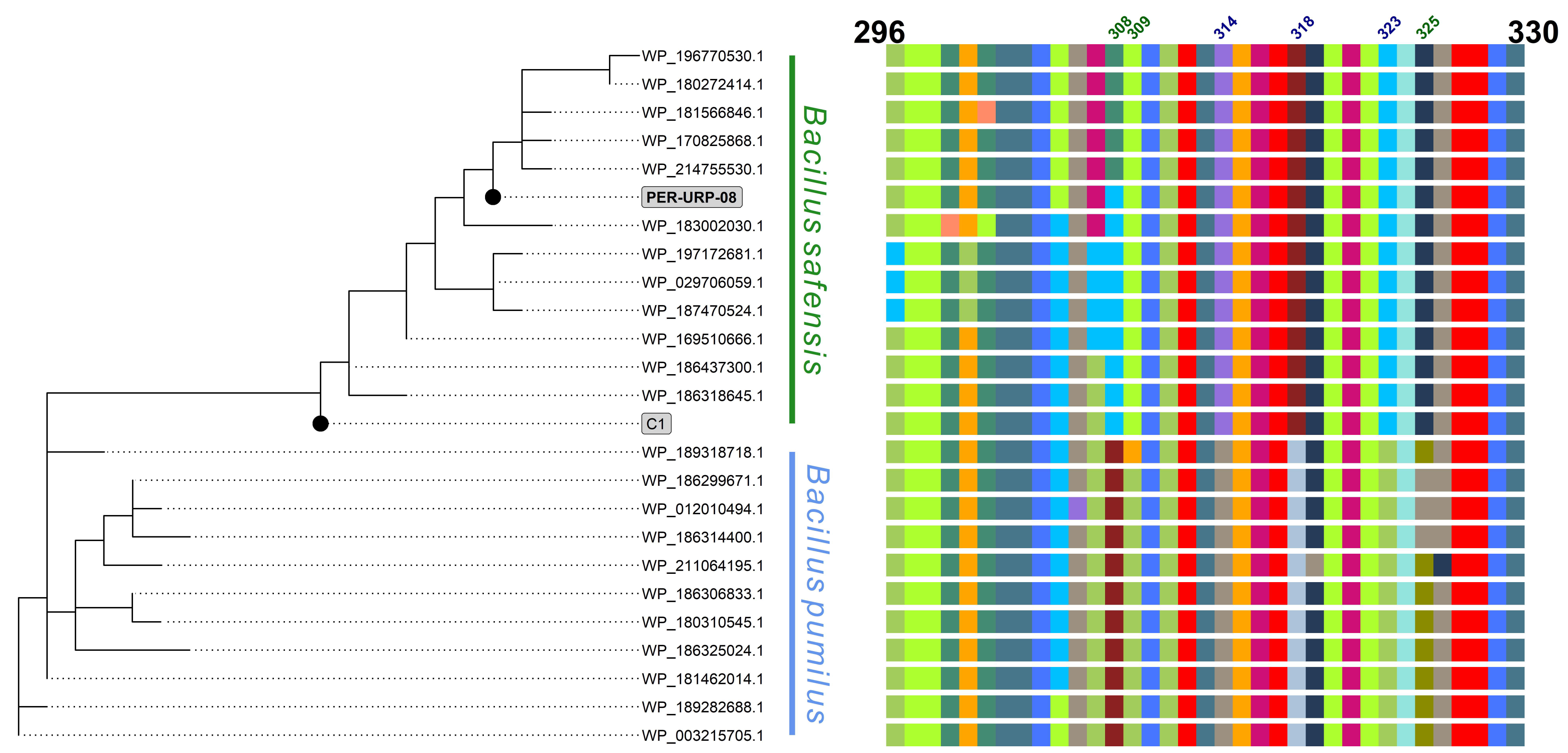

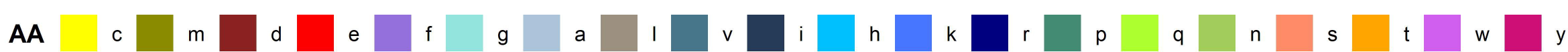





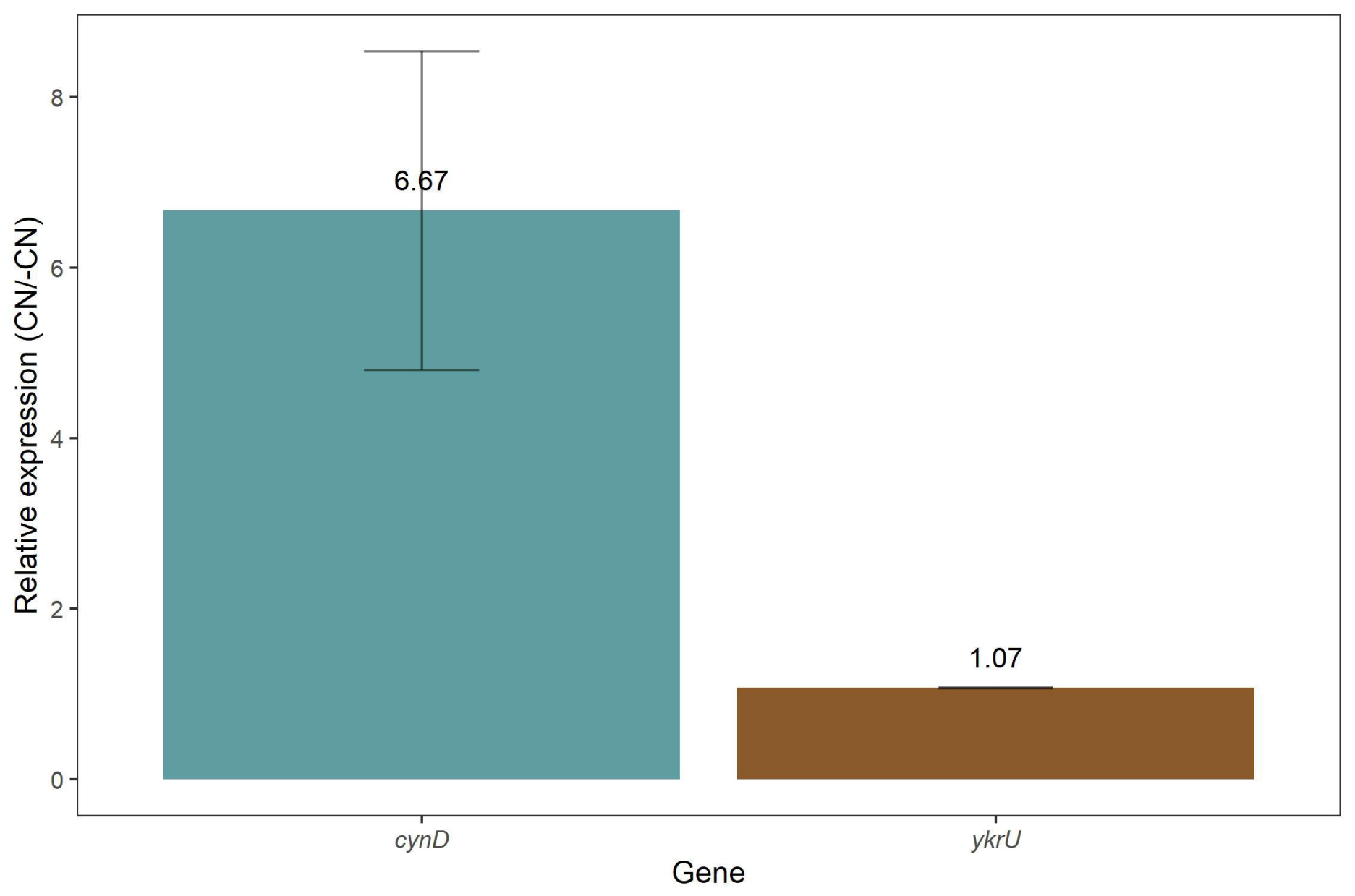

